\title{
Exercise dose in clinical practice: Should safety limits be set?
}

\author{
Anna Maria Kaleta, Ewa Lewicka \\ Department of Cardiology and Cardiac Electrotherapy, \\ Medical University of Gdansk, Poland
}

We live in an era of growing popularity of mass sports events for amateurs. It is now widely believed that almost everyone is capable of finishing a marathon given appropriate and regular training. This new approach to physical activity in society gives rise tonew tasks, problems and challenges in preventive and sports cardiology. It must be emphasized that in contrast to professional athletes, amateur athletes are a group that, until recently, has not yet been examined in the context of the relationship between intensive training and its possible effects on the cardiovascular $(\mathrm{CV})$ system. Although convincing theories indicate the possible proarrhythmogenic effect of intensive bouts of exercise, there remains a lack of data from clinical trials. Should the amateur athletes undergo regular screening programs? Should they be cardiologically monitored with regard to possible adverse effects of exercise on the CV system in the long term perspective? These are the questions that need to be answered in the near future because the trend of mass sports events among amateurs will definitely continue.

A Letter to the Editor by Leggio et al. [1] was read with great interest. The comments are highly appreciated and the findings encourage agreement that there is a growing number of subjects that exceed the recommended doses of moderateintensity weekly exercise without taking into consideration risk factors for $\mathrm{CV}$ diseases (CVD). The authors emphasize an important issue, that in such people the evolving of CVD may present with atypical, less expressed symptoms. That is why this group requires an insightful and active screening for CVD.
In the present research performed among Polish amateur marathon runners (healthy men with no history of chronic illnesses) $80 \%$ of subjects presented with electrocardiographic (ECG) variants that would be regarded as abnormalities if they were analyzed based on ECG criteria for sedentary subjects [2]. Furthermore, the enlargement of left atrium was commonly observed in $20 \%$ of participants. Atrial fibrillation (AF) is the most frequent arrhythmia in athletes. In the cohort of 40- to 65-year-old males who trained intensively, a significant risk for the development of AF has been identified [3]. Although yet, there has been no consensus as yet to whether a link between left atrial size and the occurence of supraventricular arrhythmias in athletes exists, the accumulated lifetime activity and the size of left atrium were reported as risk factors for lone AF [4]. Moreover, in the present research, when the so called 'refined criteria' of interpretation of athletes' electrocardiograms were applied [5] it was found that $15 \%$ of amateur marathon runners presented with so called training unrelated changes, that require further screening, as they may be a sign of underlying $\mathrm{CV}$ pathology. This finding may be considered as extremely important in the perspective view of preventive cardiology. It indicates that not only in professional, but also amateur athletes, an easily accessible examination such as electrocardiography is a useful tool for detection of possible cardiac abnormalities. Therefore, the claim that amateur athletes should commonly undergo an ECG screening before attending these type of competitions.

Each bout of intensive physical exercise causes a neurohormonal and proinflammatory cytokine

Address for correspondence: Anna Maria Kaleta, MD, Department of Cardiology and Cardiac Electrotherapy of Medical University od Gdansk, University Medical Centre, ul. Dębinki 7, 80-952 Gdańsk, Poland, tel: +48 5834939 10, e-mail: ania.m.kaleta@gumed.edu.pl

Received: 22.08.2017 Accepted: 06.09.2017 
response. It was postulated that repeated bouts of exercise may lead to myocardial fibrosis [6]. In approximately one-third of marathon runners, a dilation of the right atrium and ventricle was shown, and an increase in the concentration of cardiac troponin and natriuretic peptides. In some of them, small patches of fibrosis may later develop, which are the likely substrate for ventricular tachyarrhythmias [7].

In the present research (article under preparation), the effect of a marathon run on plasma concentration of inflammatory markers was investigated: fibrinogen, pentraxin 3 , neopterin, endothelin 1 , interleukin 6 , as well as markers indicating the myocardial damage: troponin (hs-TnI), B-type natriuretic peptide (BNP), atrial natriuretic peptide (NT-proANP), heart-type fatty acid binding protein (H-FABP) and growth differentiation factor 15 (GDF-15). To date, this is the first study performed on this topic among amateur marathon runners. It was found that strenuous effort i.e. the marathon run, triggers a significant inflammatory response and causes microdamage to myocardium. Both inflammation and damage disappears within a relatively short period of time, but the question arises: if these processes repeat, can they eventually have adverse effects on the myocardium? Are we able to identify subjects prone to heart damage due to intense effort among amateur athletes? Does any limit of intensive exercise exist that would undoubtedly be beneficial and safe for the $\mathrm{CV}$ system? These questions are up-to-date in the era of mass amateur sport, but they remain without answers. This is why, a debate on the need of common cardiological screening of amateur-sportsmen should be strongly recommended.

\section{Conflict of interest: None declared}

\section{References}

1. Leggio M, Bendini MG, D’Emidio S, et al. Exercise dose in clinical practice: Right is better than more. Cardiol J. 2018; 25(2): 287-288, doi: 10.5603/CJ.2018.0040.

2. Kaleta AM, Lewicka E, Dąbrowska-Kugacka A, et al. Electrocardiographic abnormalities in amateur male marathon runners. (In press). ACEM 8/2018, vol. 27.

3. Predel HG. Marathon run: cardiovascular adaptation and cardiovascular risk. Eur Heart J. 2014; 35(44): 3091-3098, doi: 10.1093/ eurheartj/eht502, indexed in Pubmed: 24408890.

4. Mont L, Tamborero D, Elosua R, et al. GIRAFA (Grup Integrat de Recerca en Fibril-lació Auricular) Investigators. Physical activity, height, and left atrial size are independent risk factors for lone atrial fibrillation in middle-aged healthy individuals. Europace. 2008; 10(1): 15-20, doi:10.1093/europace/eum263, indexed in Pubmed: 18178694.

5. Sheikh N, Papadakis M, Ghani S, et al. Comparison of electrocardiographic criteria for the detection of cardiac abnormalities in elite black and white athletes. Circulation. 2014; 129(16): 1637-1649, doi: 10.1161/CIRCULATIONAHA.113.006179, indexed in Pubmed: 24619464.

6. Kaleta AM, Lewicka E, Dąbrowska-Kugacka A, et al. Intensive exercise and its effect on the heart: Is more always better? Cardiol J. 2017; 24(2): 111-116, doi: 10.5603/CJ.2017.0039, indexed in Pubmed: 28421587.

7. Trivax JE, McCullough PA. Phidippides cardiomyopathy: a review and case illustration. Clin Cardiol. 2012; 35(2): 69-73, doi: 10.1002/clc.20994, indexed in Pubmed: 22222888. 